\title{
Estimation of changes in the Dead Sea surface water area through multiple water index algorithms and geospatial techniques
}

\author{
Al-Mashagbah A.F. ${ }^{1}$, Ibrahim M. ${ }^{1 *}$ and Al-Fugara A. ${ }^{2}$ \\ ${ }^{1}$ Department of Geographic Information System and Remote Sensing, Institute of Earth and Environmental Sciences, Al Al-Bayt \\ University, Mafraq, Jordan \\ 2Department of Engineering Survey, Faculty of Engineering, Al Al-Bayt University, Mafraq, Jordan \\ Received: 22/09/2021, Accepted: 01/12/2021, Available online: 03/12/2021 \\ *to whom all correspondence should be addressed: e-mail: majed.ibrahim@aabu.edu.jo \\ https://doi.org/10.30955/gnj.004018
}

\section{Graphical abstract}

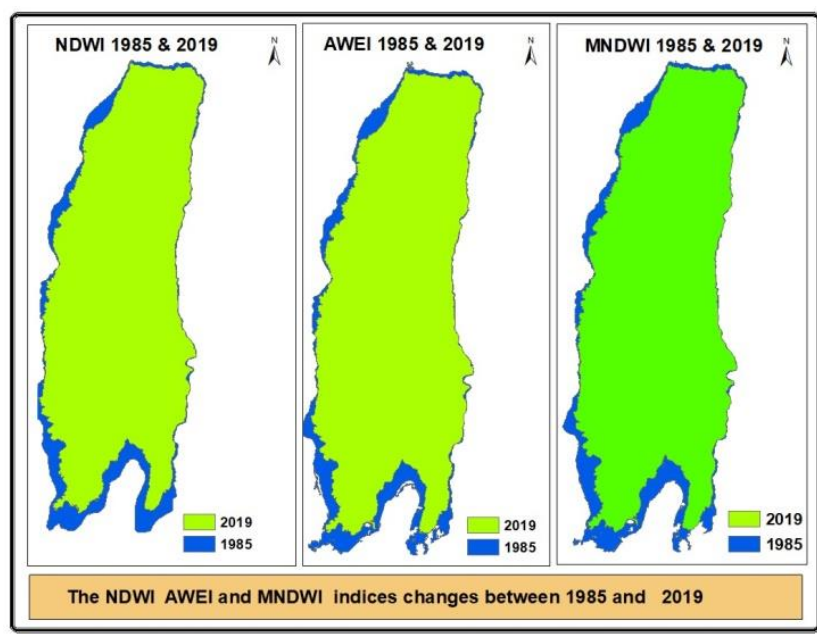

\section{Abstract}

The study calculated the changes in the Dead Sea surface area from 1984 to 2019. The satellite images of 1985, 1990, 2000, 2010, and 2019 were classified by applying four different methods to estimate the changes in the Dead Sea surface water area. The methods included normalized difference water index (NDWI), modified normalized differences water index (MNDWI), automated water extraction Index (AWEI), and ISO cluster unsupervised classification. The results revealed a decrease of $76.63 \mathrm{sq}$. $\mathrm{km}$ area that accounts for an average of $11.27 \%$ sea area. The statistical model predicted that the Dead Sea surface area will shrink by half within the next 143 years, and the sea will be completely dried by 2305 if appropriate measures are not taken by decision-makers to avoid further reduction of the surface area.

Keywords: Water indices, GIS, Geospatial, Dead Sea, Jordan.

\section{Introduction}

Modern techniques of remote sensing and geographic information systems facilitate the detection and monitoring of water bodies in various regions of the world without making direct contact. The signature radiation of each object on the Earth's surface that distinguishes it from others is known as the reflectance band. Remote sensing and geographic information systems employ reflectance bands to remotely analyze the geographic components (Pekel et al., 2016; Donchyts et al., 2016; Xu, 2006; McFeeters, 1996). The Dead Sea that is located in western Jordan is of key importance. Seasonal monitoring of the Dead Sea is necessary to detect the changes or decline in its surface area that occurred in recent years. A high-saline lake is located along the Dead Sea transform fault system in the Rift Valley of Jordan (Nehorai et al., 2009; Yechieli et al., 1998). This system separates Arabian and African Plates between Palestine, Jordan, and Israel. The Dead Sea is the lowest point on the Earth's surface (Nehorai et al., 2009) that is 430 meters below sea level. The Dead Sea is small expanding to a length of about $52 \mathrm{~km}$ and width of 13 $\mathrm{km}$. It is one of the most famous global natural landmarks and contains a high proportion of salts and minerals mainly including potassium, magnesium, chloride salts, and bromide. In addition to the Zarqa Ma'in watershed and wadi al-Mujib, the Jordan River is the main tributary of the Dead Sea. An extremely hot and dry desert climate of this region leads to a higher evaporation rate that significantly contributes to decreasing the sea surface area and increasing the salts concentration. Different factors critically contribute to the continuous decline of the Dead Sea surface area, mainly including 1 ) intensive water usage from Jordan River that is the most important tributary 2) Higher evaporation rates in the region, and 3) overpumping of brine seawater into the salt ponds of Palestine, Jordan, and Israel for the extraction of salt and minerals such as potassium, bromine, magnesium chlorides, and other derivatives.

The factors such as the reduced precipitation in the nearby mountains, decreased groundwater level due to climate change, and tourist and industrial activities have further aggravated the situation. Several techniques have been followed previously to study the Dead Sea during different periods. Yechieli et al., (1998), and Anati and Shasha (1989) estimated the decrease in the Dead Sea level at a rate of 80 
$\mathrm{cm} /$ year, whereas Gertman and Hecht (2002) reported a diminishing rate of $60 \mathrm{~cm} /$ year. Lensky et al., (2005) concluded a sea-level decreasing rate of $100 \mathrm{~cm} /$ year during the last decade. This study aims to verify the decline in the Dead Sea surface area during the study period. The study also applied remote sensing and geographic information systems to elaborate on the decreasing rate of sea surface area and water level during the last four decades.

Many external factors have an effect on to water bodies, wherever the extracted spectral features may well be a mix of water and different categories like built-up lands distortion. In 2006, Xu proposed a modified normalized difference water index (mNDWI) according NDWI, and made the amendment by substitution the NIR band with the shortwave-infrared (SWIR) band, that helped to remove distortions from built-up lands. However, the best thresholds vary based on locations and time, that mean every index have may well be appropriate in some cases however, it isn't appropriate for different cases. Therefore, the indices were used in this study based on the spectral features used in Landsat 8 and conditions of the study area (Xu. 2006, Zhou et al., 2017). Furthermore, the performance of AWEI, NDWI, NDVI, and MNDWI water indicators to detect the changes in the Dead Sea area during certain periods was also evaluated.

\section{Study area}

The study area is located between Jordan, Israel, and Palestine. It is located approximately $55 \mathrm{~km}$ southwest of the capital, Amman, and approximately 24 kilometers east of Jerusalem. The area covers parts of the Madaba, Balqa, and Karak governorates in Jordan. The total area is about $601 \mathrm{sq}$. km with the following coordinates: latitudes $31^{\circ} 17^{\prime}$ $42^{\prime \prime} \mathrm{N}$ and $31^{\circ} 46^{\prime} 96^{\prime \prime} \mathrm{N}$ and longitudes $35^{\circ} 23^{\prime} 79^{\prime \prime} \mathrm{E}$ and $35^{\circ} 36^{\prime} 0.07^{\prime \prime}$ (Figure 1).

Generally, altitudes in the eastern and western parts of the study area are high. Figures 2 and 3 present a 3D model view of altitudes, and east-west and north-south crosssections of the Dead Sea area, respectively.

The Dead Sea area is characterized by dry air and sunny skies throughout the year. The region receives an average rainfall of $50 \mathrm{~mm} /$ annum whereas the yearly average temperature ranges between $32^{\circ} \mathrm{C}$ to $39^{\circ} \mathrm{C}$ in summer and 20 to $23^{\circ} \mathrm{C}$ in winter. The average percentage of humidity in the area is quite low (35\%) (Al-Mashagbah and $\mathrm{Al}$ Farajat, 2013). The Dead Sea region is among the key tourist areas for environmental physiotherapy. A combination of distinguished natural factors places this area in a competitive position for medical and clinical tourism, and environmental physiotherapy. The unique moisture-free climatic properties and sulfuric springs are known to cure various skin diseases. The World Health Organization recognized this area as a global center in 2011 for treating different skin diseases.

\section{Experimental methods}

\subsection{Image pre-processing}

ArcMap software was used for the pre-processing of Landsat images. The images downloaded from the "Earth Explorer website" were re-projected using Jordan Transverse Mercator (JTM) in the unit of meter to calculate study area in each year. In other hand decimal degree projection was used to display the location of study area as shown in Figure 1. Georeferencing of image data was carried out using georeferencing toolbar whereas the study area polygon shapefile served as a reference layer. Five multispectral satellite images were downloaded from the United States Geological Survey (USGS) Earth Explorer website (https://earthexplorer.usgs.gov). The images were acquired on Aug 21, 1985; Aug 3, 1990; Aug 25, 2000; Sep 6, 2010; and Aug 6, 2019, during the dry summer (with minimum cloud cover) to detect the changes in the Dead Sea surface area. The first and second images represent Landsat TM, the third and fourth images represent Landsat ETM+, and the fifth is from the Landsat $8 \mathrm{OLI}$ imagery for path 174 , row 38 , covering the Dead Sea area. Image processing was carried out using ArcGIS 10.4 image analyst extension. Landsat data obtained from the US Geological Survey has already been orthorectified and georegistered, therefore, these steps were excluded.

\subsection{Water indices}

These are the mathematical models to distinguish the contact line between the water masses and adjacent land. These models facilitate accurate defining of the shoreline in multi-time-varying images (Xu, 2006; Mcfeeters, 1996). Two or more spectral bands in the satellite image are often used to apply these mathematical models (Ji et al., 2009).

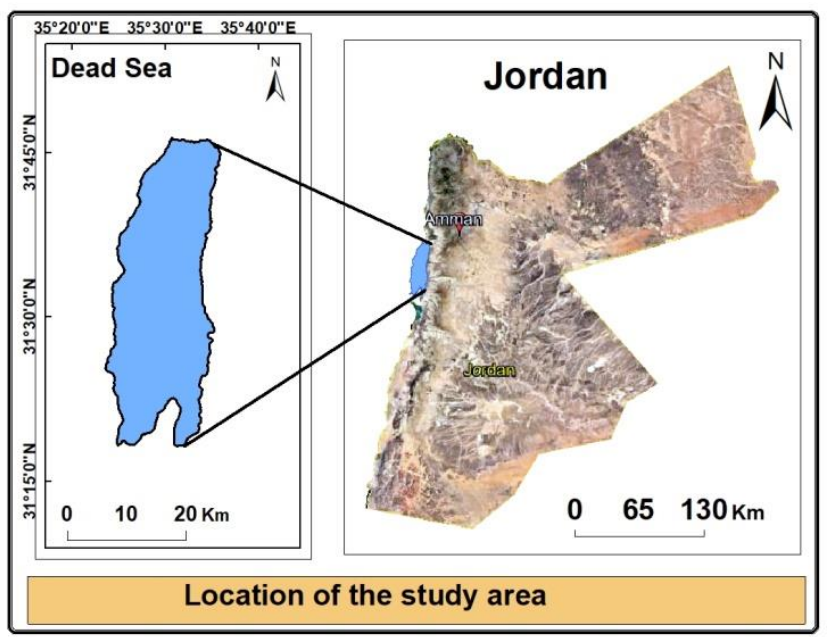

Figure 1. The map of Jordan presenting the location of the Dead Sea.

\subsubsection{Normalized difference water index (NDWI)}

The normalized difference water index (NDWI) is a new method that defines the features of open water and enhances its presence and visibility in remotely sensed digital images (Li et al., 2013; Gao, 1996). NDWI method uses reflected radiation in the visible green light and nearinfrared bands as shown in equation 1 (Mcfeeters, 1996):

$$
\text { NDWI }=(\text { Green }-N I R) /(\text { Green }+ \text { NIR })
$$


Where NIR is Near-infrared, NDWI value ranges from -1.0 to 1.0. The positive values represent water area whereas the negative values represent non-water lands (Mcfeeters, 1996).

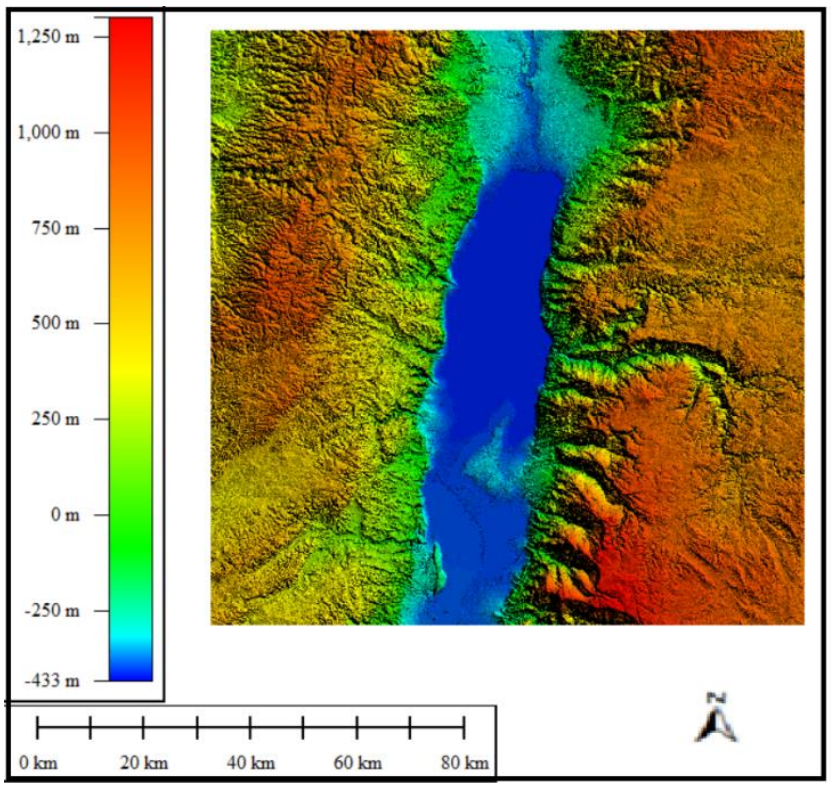

Figure 2. 3D-model view of the study area.

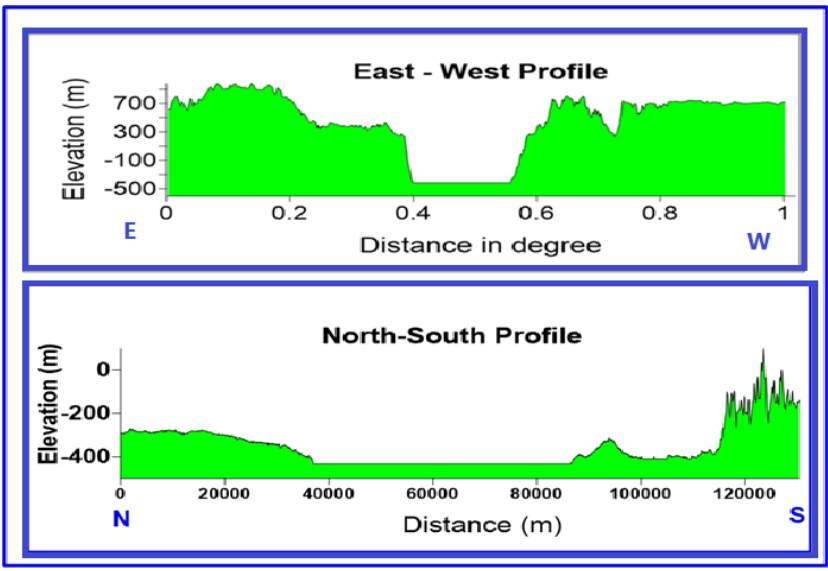

Figure 3. Topographic $\mathrm{E}-\mathrm{W}$ and $\mathrm{N}$ - S profiles of the study area.

\subsubsection{Modified normalized differences water index (MNDWI)}

The MNDWI technique is almost similar to NDWI with only one exception of using a middle infrared band instead of a near-infrared band. This is simply a masking procedure that separates the land. Primarily, it is used for the removal of built-up land noise. In the MNDWI method, the water areas possess higher pixel values as compared to urban or vegetation areas with a lower pixel value. Therefore, it delineates the water class from other classes. This method can also efficiently eliminate shadow noise from the water data without involving advanced procedures (Han, 2005). The replacement of near-infrared band in NDWI with visible green light and middle infrared bands (MIR) in MNDWI occurs as shown in equation 2 (Xu \& H.Q., 2006):

$$
\text { MNDWI }=(\text { Green }- \text { MIR }) /(\text { Green }+ \text { MIR })
$$

\subsubsection{Automated water extraction index (AWEI)}

The automated water extraction Index (AWEI) is the most important method to assess the changes in the water area of water bodies. This index locates water with high precision, particularly in the mountainous areas with deep terrain where shadow causes the main classification error. AWEI provides accurate classification in areas where other classification methods could not correctly identify the features either due to dark surfaces or shadows (Feyisa et al., 2014). AWEI distinguishes between the pixels of water bodies and other lands for identifying agricultural and urban areas, and other classes present in the satellite images (Feyisa et al., 2014). AWEI uses the reflectance of the Short-wave infrared (SWIR), near-infrared, visible green, and visible blue light bands as shown in equations 3 and 4 (Feyisa et al., 2014):

$$
\begin{aligned}
& \text { AWEIsh }=\text { Blue }+2.5 \times \text { Green }-1.5 \times(\mathrm{NIR}+ \\
& \text { SWIR } 1)-0.25 \times \text { SWIR } 2 \\
& \text { AWEInSh }=4 \times(\text { Green }- \text { SWIR } 1)-(0.25 \times \mathrm{NIR}+ \\
& 2.75 \times \text { SWIR2 })
\end{aligned}
$$

\subsubsection{ISO cluster unsupervised classification}

Iso clustering is a simple and best-known unsupervised machine algorithm. It identifies the number of classes $(x)$ and based on the spectral similarity dispenses each data pixel to the closest cluster while keeping the classes as small as is acceptable (Lillesand, et al., 2008).

Iso Cluster technique or migrating means technique employs a modified iterative optimization clustering procedure. This technique automatically finds clusters and several classes in an image to yield a classified image empirically specified by the classifier based on the land cover of the study area. Iso Cluster unsupervised classification extension in the ArcGIS 10.4.1 software was used to classify the AWEI, NDWI, and MNDWI images into different classes. Subsequently, depending on the threshold value of the water indices, each image was converted only into two classes (water and non-water) for studying the changes in water cover during the last four decades.

Initially, the water indices were extracted from the images. Depending on the threshold values of the indices, the unsupervised post-classification methods were applied to separate the water from non-water areas. The derived water indices were used to produce a classified map to determine the changes. Later on, the raster image was converted into a vector-based file containing a polygon having an attribute value equal to one (to represent water) or zero (to represent non-water areas). During the next step, the vector map was converted to a separate shapefile to represent and calculate the Dead Sea polygon area, and the loss of water area over the last 35 years.

\subsection{Accuracy assessment}

The accuracy verification of digitally classified water index images is necessary. The verification is carried out by counting the errors in the maps and comparing the classified map data with the corresponding Google Earth 
reference map. To assess the accuracy of the classification and extraction of water areas in the study area, 150 random samples of different locations in the study area were selected for each image using the ArcMap software. These random points were converted to Keyhole Markup Language (KML) format and opened in the high-spatialresolution Google Earth software to match the classification samples with the real information. The Kappa coefficient and overall accuracy indicators were applied to evaluate the accuracy of different water index maps (Ibrahim, 2016). The Kappa coefficient and overall accuracy indicators were calculated as shown in equations 5 and 6 :

$$
\begin{aligned}
& \text { Overall accuracy }(O A)=(N W+T W) / N \\
& \text { Kappa coefficient }=(N *(N W+T W)-F) /(N 2-F)
\end{aligned}
$$

Where: $\mathrm{N}$ is the number of random points; TW is the number of correct water pixels; UW is the number of undetected water pixels; IW is the number of incorrect water pixels; NW is the number of correctly rejected nonwater pixels; $F$ is $(U W+T W)(I W+T W)+(I W+N W)(U W+N W)$.

\section{Results and discussion}

This study employs a geographic information system and remote sensing satellite imagery to confirm the changes in the Dead Sea surface area. Four different methods were applied to differentiate among the satellite images of the Dead Sea surface areas captured in 1985, 1990, 2000, 2010, and 2019. These methods included normalized difference water index (NDWI), modified normalized differences water index (MNDWI), automated water extraction Index (AWEI), and Iso Cluster unsupervised classification. During the study, water and land areas were separated by using a threshold value. The water index images revealed fluctuating and variable threshold values according to the type of water indices and time intervals (Komeil et al., 2014).

The water pixels are known to have positive values whereas other land cover areas exhibit zero or lower values (Ji et al., 2009). The pixel water area was noted to have much higher NDWI, MNDWI, and AWEI threshold values as compared to surrounding land cover types. The NDWI and MNDWI based water threshold values were observed to be generally greater than 0.3 , which further increased with the rise in water salinity. This is evident from the threshold values in the shallow brine intake water station area in the south of the Dead Sea on the Lisan peninsula belonging to the Jordanian Arab Potash Company (Figure 4).

Table 1. Summary of surface water changes from 1985- 2019 based on different indices

\begin{tabular}{ccccc}
\hline Year & NDWI Area $\left(\mathbf{k m}^{\mathbf{2}}\right)$ & MNDWI Area $\left(\mathbf{k m}^{2}\right)$ & AWEI Area $\left(\mathbf{k m}^{\mathbf{2}}\right)$ & Average Area $(\mathbf{k m})$ \\
\hline 1985 & 680.12 & 679.04 & 681.41 & 680.19 \\
\hline 1990 & 659.19 & 658.43 & 661.89 & 659.87 \\
\hline 2000 & 644.23 & 643.37 & 646.42 & 644.67 \\
\hline 2010 & 621.90 & 622.43 & 626.08 & 623.47 \\
\hline 2019 & 603.37 & 603.57 & 605.73 & 604.22 \\
\hline Total change & -76.75 & -75.47 & -75.68 & 75.97 \\
\hline \% change & -11.28 & -11.11 & -11.11 & -11.17 \\
\hline
\end{tabular}

\begin{tabular}{|c|c|c|c|c|}
\hline Year & Average Area (sq.km) & $\%$ Area & \% Change & \% Decrease \\
\hline 1985 & 680.19 & 100 & 100 & 0 \\
\hline 1990 & 659.87 & 97.01 & -2.99 & -2.99 \\
\hline 2000 & 644.67 & 94.78 & -5.22 & -2.30 \\
\hline 2010 & 623.47 & 91.66 & -8.34 & -3.29 \\
\hline 2019 & 604.22 & 88.83 & -11.17 & -3.09 \\
\hline Total change & 75.97 & & & \\
\hline
\end{tabular}

Table 2. Percent decrease in Dead Sea areas from 1985 to 2019

The areas calculated from the Dead Sea satellite image captured in 1985 using MNDWI, AWEI, and NDWI indicators were noted as $679 \mathrm{sq} . \mathrm{km}, 681.41 \mathrm{sq} . \mathrm{km}$, and 680.12 sq. km, respectively, having an average of 680.19 sq. km. MNDWI, AWEI, and NDWI indicators estimated the areas from the image captured in 1990 as $658.53 \mathrm{sq.} \mathrm{km}$, 661.89 sq. km, and 659.19 sq. km, respectively, having an average of $659.87 \mathrm{sq}$. $\mathrm{km}$. The classification of satellite images captured in 2000 presented the surface water areas as 643.37 sq. km, 646.42 sq. km, and 644.23 sq. km, respectively, with an average of $644.67 \mathrm{sq} . \mathrm{km}$. The areas calculated from the satellite image of 2010 were equal to 622.43 sq. km, 626.08 sq. km, and 621.90 sq. km, respectively, with an average of $644.67 \mathrm{sq} . \mathrm{km}$. The final satellite image of 2019 revealed that the Dead Sea surface areas were reduced to $603.57 \mathrm{sq} . \mathrm{km}, 605.73 \mathrm{sq} . \mathrm{km}$, and 601.37 sq. km, respectively, having an average of 603.56 sq. km. These results are presented in Table 1 and Figure 5.

The Dead Sea surface area cover significantly reduced during the mentioned years. Table 2 depicts the decrease in surface water area by $2.99 \%$ (20.32 sq. km), 2.30\% (15.2 sq. $\mathrm{km}$ ), $3.29 \%$ (21.2 sq. km), and $3.09 \%$ (19.25 sq. km) during 1985-1990, 1990-2000, 2000-2010, and 20102019, respectively. A significant reduction (76.63 sq. $\mathrm{km}$ ) in the Dead Sea surface water area has occurred during the last 34 years that accounts for an average of $11.27 \%$ of the total sea area, as shown in Table 2 and Figure 6. 


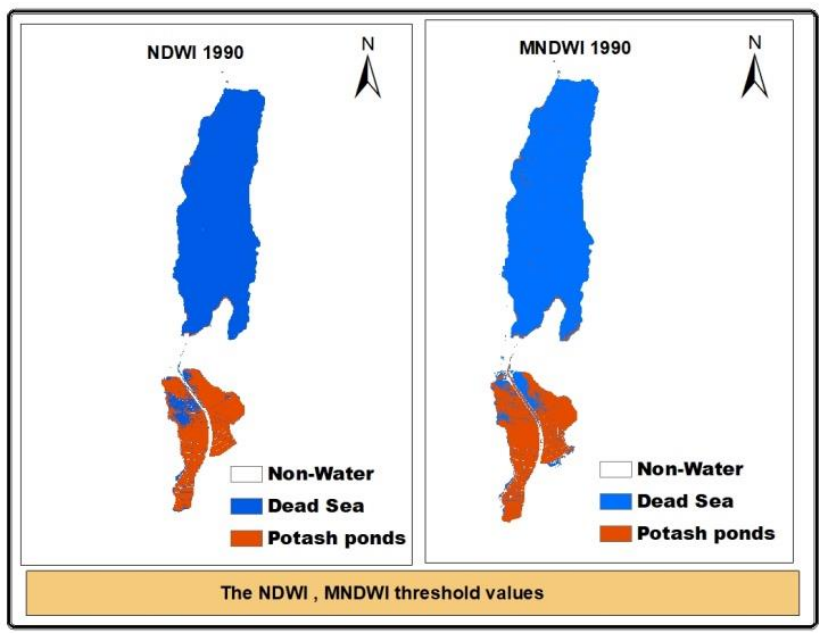

Figure 4. Threshold values for NDWI and MNDWI water indices 1990.

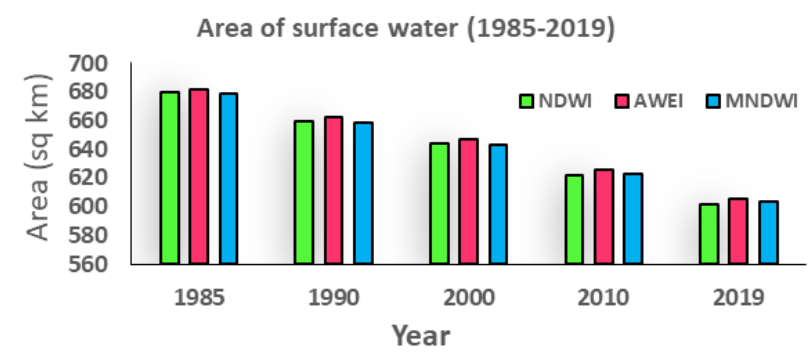

Figure 5. Comparison of changes in surface water area from 1985 to 2019.

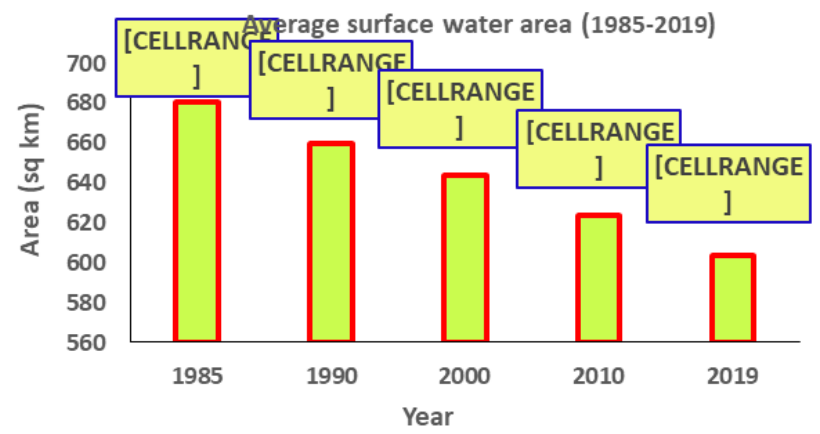

Figure 6. Changes in the Dead Sea Surface area from 1985 to 2019.

Figure 7 illustrates the spatial changes in the Dead Sea seawater area from 1985 to 2019. It shows an overlay of the 2019 vector on top of the 1985 spatial distribution vector of the Dead Sea surface water. Based on the results, it is noteworthy that these changes mainly occurred on the southern and western sides of the Dead Sea.

The rate of decreasing the Dead Sea water area was found to be about 2.25 sq. km per year. Mathematical models further predicted future sea surface changes (Figure 8). Available data and mathematical models demonstrated the depletion and complete drying of the Dead Sea in the next 280 years if practical solutions are not implemented.

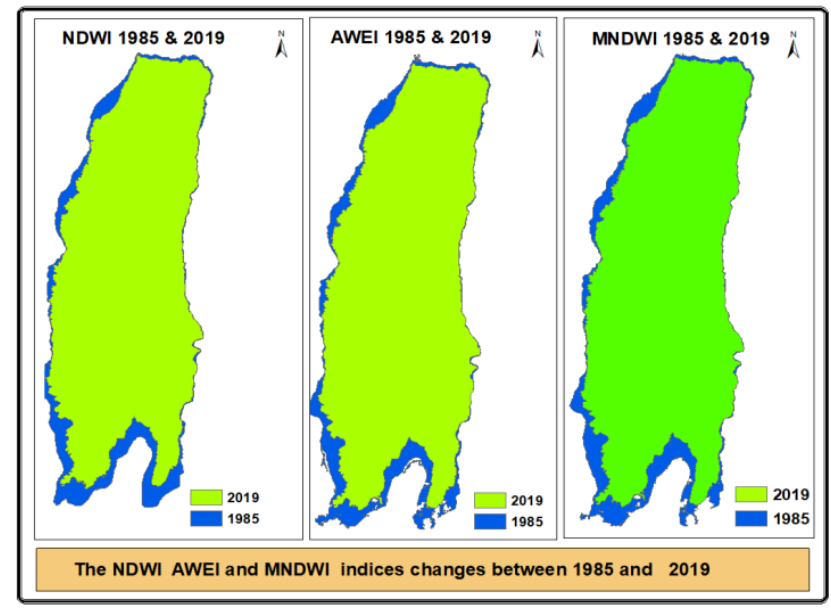

Figure 7. The seawater changes were based on the NDWI, AWEI, and MNDWI indices between 1985 and 2019.

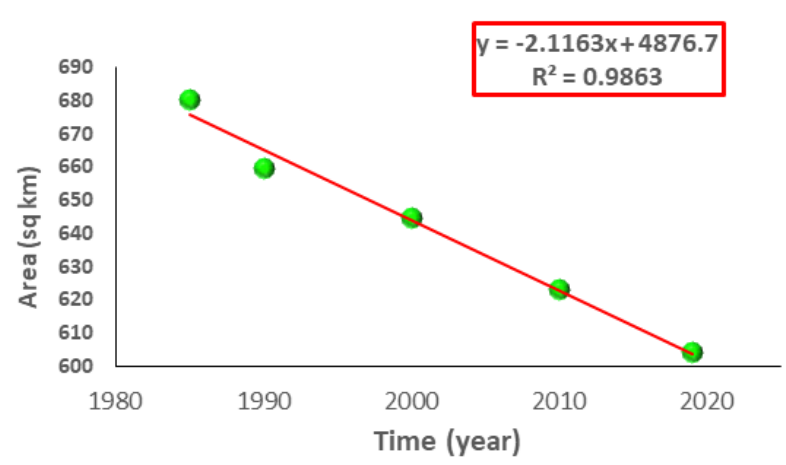

Figure 8. A statistical model predicting the future changes in the Dead Sea area.

The accuracy of classification and extraction of water areas was evaluated by randomly selecting 150 samples of different locations from each satellite image using the ArcMap software. These random points were converted to KML format and opened in the high-spatial-resolution Google Earth software to ensure that some of the classification samples match the reality (Figure 9). The overall accuracies of the classified water index images ranged from $98.67 \%$ to $100 \%$ whereas the Kappa coefficient indicator values remained as 0.97 to 1.0 (Table 3). The insignificant error in overall accuracy and Kappa coefficient was caused by the difference in dates between the satellite images and the reference Google Earth images (up to four months in some images). Therefore, in some cases, it led to the classification of water values as nonwater or vice versa as marginal points between water and non-water pixels. It could have been correct and identical if the two images were taken simultaneously.

\section{Conclusion}

This study applied geographic information systems and remote sensing techniques to assess the changes in the Dead Sea surface area, in Western Jordan over the past 35 years. Four water index based algorithms were followed to recognize the differences in the Dead Sea surface area at different intervals. Normalized difference water index (NDWI), modified normalized differences water index (MNDWI), automated water extraction Index (AWEI), and ISO Cluster unsupervised classification methods analyzed 
the satellite images captured in 1985, 1990, 2000, 2010, and 2019. The results helped in conceiving some valuable conclusions. The most important finding was that the surface area of the Dead Sea has decreased by $76.63 \mathrm{sq.} \mathrm{km}$ during the last 35 years that is approximately $11.27 \%$ of the total sea area. The rate of the annual decrease of the water surface area was calculated as $2.25 \mathrm{sq}$. km. A statistical model was also designed to predict the future status of the
Dead Sea, which projected the shrinkage of the Dead Sea surface area by half within the next 143 years. The model further revealed that and the Dead Sea will completely dry around 2305 if necessary actions are not taken. The threshold values were utilized to distinguish water from non-water areas that varied with time and type of water indices used for the calculations.

Table 3. The overall accuracy and Kappa Coefficient of the classified images

\begin{tabular}{|c|c|c|c|c|c|c|}
\hline \multirow{2}{*}{ Year } & \multicolumn{2}{|c|}{ NDWI } & \multicolumn{2}{|c|}{ MNDWI } & \multicolumn{2}{|c|}{ AWEI } \\
\hline & OA & Kappa & OA & Kappa & OA & Kappa \\
\hline 1985 & 99.34 & 0.99 & 100 & 1 & 99.35 & 0.98 \\
\hline 1990 & 100 & 1 & 98.67 & 0.97 & 100 & 1 \\
\hline 2000 & 99.33 & 0.98 & 100 & 1 & 100 & 1 \\
\hline 2010 & 100 & 1 & 99.35 & 0.98 & 99.33 & 0.98 \\
\hline 2019 & 100 & 1 & 100 & 1 & 100 & 1 \\
\hline
\end{tabular}

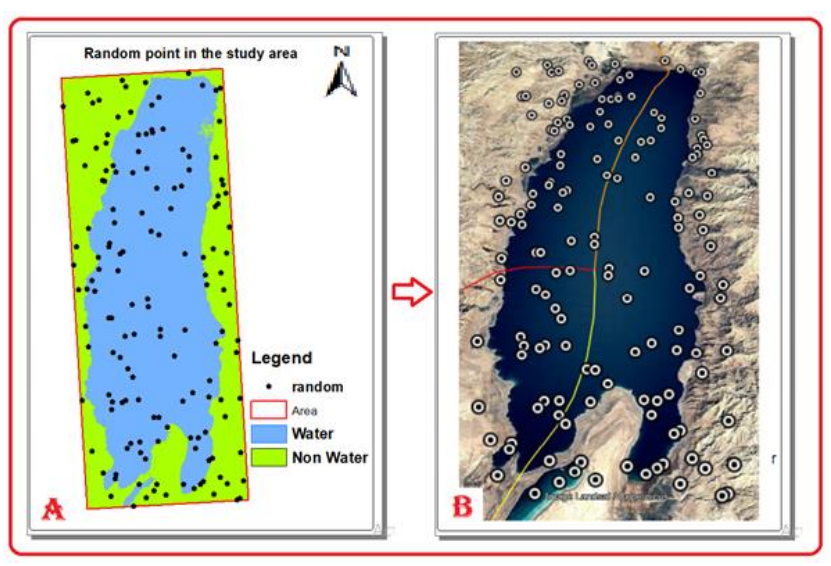

Figure 9. Random points in ArcMap (A) and Google Earth (B).

The overall classification accuracy of the captured images during 1985, 1990, 2000, 2010, and 2019 ranged from $98.67 \%$ to $97.53 \%$, which reveals a high validity of the results. Generally, the threshold values of NDWI and MNDWI for the water area were noted to be greater than 0.3 , which further increased with the rise in water salinity. MNDWI, AWEI, and NDWI indicators predicted very close surface areas of the Dead Sea with only negligible differences. The results also revealed that most of the decline in the sea surface area occurred on the southern and western sides of the Dead Sea. The study further demonstrated that the mapping of the Landsat TM, ETM, and OLI high-resolution satellite images utilizing remote sensing-based water indices and unsupervised classification techniques is very effective to identify the changes in surface water area over longer periods and provides accurate information for the decision-makers, which is matching with results that it was concluded by Zhou et al 2017, where is found that the water indices had reasonable good performances in open surface water body mapping (Herndon et al., 2020, Zhou et al., 2017). In addition, these results shown that the rates of declining sea area were found to be alarming that require serious and swift actions to save the Dead Sea.

\section{Recommendations}

The construction of the Bahrain Canal project is the most expeditious solution that can transfer sufficient water to the Dead Sea. This project depends on a channel to link the Dead Sea and the Red Sea (Gulf of Aqaba) or the Mediterranean Sea, however, there is a difference of approximately 400 meters as the Dead Sea is the lowest area on the surface of the earth below sea level. The rapid decline in the Dead Sea surface could be compensated through this project and it can further facilitate the construction of a power generation plant and a desalination water plant to benefit the Dead Sea countries. The shrinking of the Dead Sea surface area has resulted in environmental problems in that region such as increased salinity in Dead Sea water, decreased groundwater levels, and the formation of excavation. These issues are affecting the lives of local inhabitants of the region. The establishment of a desalination plant for the Red Sea water can be another possible solution. The freshwater from this plant can be channeled into the Dead Sea to save it from drought. Building a full geographic information system for the Dead Sea region is important as it will help to timely estimate the changes and decision-making. The data of this GIS system must also be updated regularly.

\section{References}

Al-Mashagbah A. and Al-Farajat M. (2013), Assessment of spatial and temporal variability of rainfall data using kriging, Mann Kendall test and the Sen's slope estimates in Jordan from 1980 to 2007, Journal of Environmental and Earth Sciences, 5 (10) 611-618.

Anati, D. A. and Shasha, S. (1989), Dead Sea surface-level changes, Israel Journal of Earth-Sciences, 38(1), 29-32.

Donchyts G., Baart F., Winsemius H., Gorelick N., Kwadijk J. and Van de Giesen N. (2016), Earth's surface water change over the past 30 years, Nature Climate Change, 6(9), 810-813.

Feyisa G.L., Meilby H., Fensholt R. and Proud S.R. (2014). Automated water extraction index: a new technique for surface water mapping using Landsat imagery, Remote Sensing of Environment, 140, 23-35.

Gao, B.C. (1996), NDWI-a normalized difference water index for remote sensing of vegetation liquid water from space, Remote Sensing of Environment, 58, 257-266. 
Gertman I. and Hecht, A. (2002), The dead Sea hydrography from 1992 to 2000, Journal of Marine Systems, 35(3-4), 169-181.

Han-Qiu, X.U. (2005), A study on information extraction of water body with the modified normalized difference water index (MNDWI), Journal of Remote Sensing, 5, 589-595.

Herndon, K., Muench, R., Cherrington, E., and Griffin, R. (2020), An assessment of surface water detection methods for water resource management in the Nigerien Sahel. Sensors, 20(2), 431.

Ji L., Zhang L. and Wylie, B. (2009), Analysis of dynamic thresholds for the normalized difference water index, Photogrammetric Engineering and Remote Sensing, 75(11), 1307-1317.

Lensky N.G., Dvorkin Y., Lyakhovsky V., Gertman I. and Gavrieli, I. (2005), Water, salt, and energy balances of the Dead Sea, Water Resources Research, 41(12).

Li W., Du Z., Ling F., Zhou D., Wang H., Gui Y., Sun B. and Zhang, X. (2013), A comparison of land surface water mapping using the normalized difference water index from TM, ETM+ and ALI, Remote Sensing, 5, 5530-5549.

Lillesand T.M., Kiefer R.W. and Chipman J.W. (2008), Remote sensing and image interpretation, (6th Ed.), John Wiley \& Sons, Inc., Hobokan, NJ, USA, 585-587.

McFeeters, S.K. (1996), The use of the normalized difference water index (NDWI) in the delineation of open water features, International Journal of Remote Sensing, 17, 1425-1432.

Nehorai R., Lensky I.M., Lensky N.G. and Shiff, S. (2009), Remote sensing of the Dead Sea surface temperature, Journal of Geophysical Research: Oceans, 114(C5).

Pekel J.F., Cottam A., Gorelick N. and Belward A.S. (2016), Highresolution mapping of global surface water and its long-term changes. Nature, 342(6160), 850-853.

Rokni K., Ahmad A., Selamat A. and Hazini S. (2014), Water feature extraction and change detection using multi temporal Landsat Imagery, Remote Sensing, 6, 4173-4189.

United States Geological Survey Metadata, Metadata Retrieved from Earth Explorer: https://earthexplorer.usgs.gov/ metadata/10880/1174275/.

United States Geological Survey. (2017), (United States Geological Survey) Retrieved March 2017 from Earth Explorer - USGS: https://earthexplorer.usgs.gov/distribution.

Verbyla D. (2013), Estimating Classification Accuracy Using ArcGIS, Retrieved May 2017, from https://www.youtube. com/watch?v=9dGjuEQie7Y\&t=2s.

Xu H.Q. (2006), Modification of Normalized Difference Water Index (MNDWI) to Enhance Open Water Features in Remotely Sensed Imagery, International Journal of Remote Sensing, 27, 3025-3033.

Yechieli Y., Gavrieli I., Berkowitz B. and Ronen, D. (1998), Will the Dead Sea die? Geology, 26(8), 755-758.

Zhou, Y.; Dong, J.; Xiao, X.; Xiao, T.; Yang, Z.; Zhao, G.; Zou, Z.; Qin, $Y$. (2017). Open surface water mapping algorithms: $A$ comparison of water-related spectral indices and sensors. Water, 9, 256. 